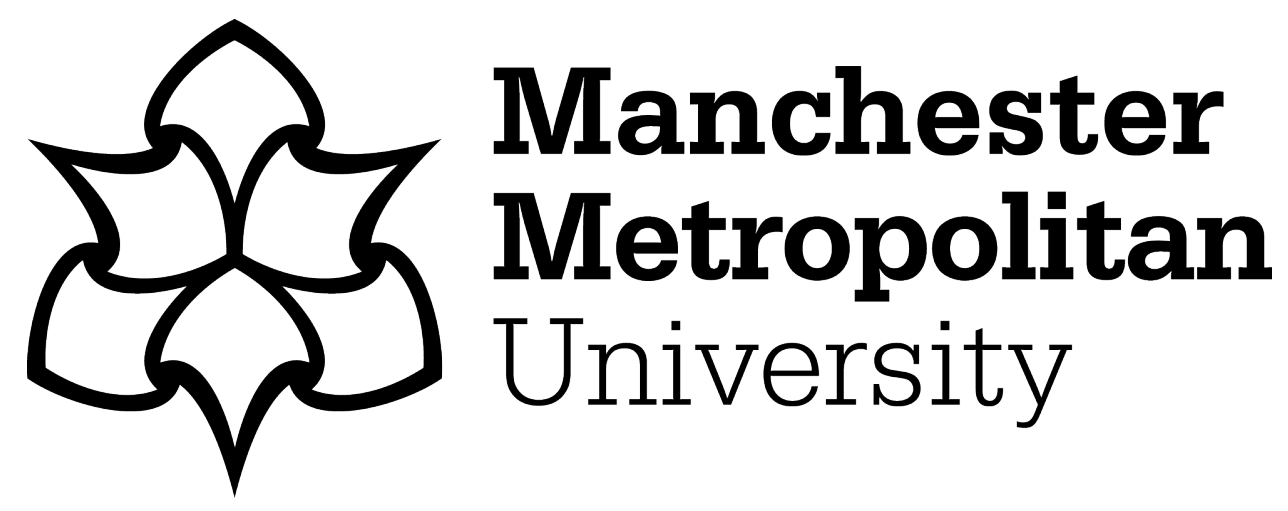

Sharp, Charlotte, Bresnen, Mike ORCID logoORCID: https://orcid.org/00000002-3295-8235, Austin, Lynn, McCarthy, Jillian, Dixon, William and Sanders, Caroline (2021) Implementing disruptive technological change in UK healthcare: exploring development of a smart phone app for remote patient monitoring as a boundary object using qualitative methods. Journal of Health Organization and Management, 35 (2). pp. 141-159. ISSN 14777266

Downloaded from: https://e-space.mmu.ac.uk/626972/

Version: Accepted Version

Publisher: Emerald

DOI: https://doi.org/10.1108/JHOM-07-2020-0295

Please cite the published version 


\section{Implementing disruptive technological change in UK healthcare: exploring development of a smart phone app for remote patient monitoring as a boundary object using qualitative methods}

Charlotte A Sharp (MRCP, MBChB), ${ }^{1}, 23$ Mike Bresnen, ${ }^{4}$ Lynn Austin, ${ }^{1}{ }^{3}$ Jill McCarthy, ${ }^{2}$ William G Dixon, ${ }^{1,} 678$ Caroline Sanders ${ }^{135}$

1. National Institute for Health Research Collaboration for Leadership in Applied Health Research and Care, Greater Manchester, Salford Royal NHS Foundation Trust, Salford, UK.

2. Alliance Manchester Business School, The University of Manchester, Manchester, UK

3. National Institute for Health Research School for Primary Care Research, The University of Manchester, Williamson Building, Oxford Road, Manchester, UK

4. Manchester Metropolitan University, Faculty of Business \& Law

5. National Institute for Health Research Greater Manchester Patient Safety Translational Research Centre, The University of Manchester, Manchester, UK

6. Arthritis Research UK Centre for Epidemiology, Division of Musculoskeletal and Dermatological Sciences, School of Biological Sciences, The University of Manchester, Manchester; UK

7. Health eResearch Centre, The UK Farr Institute of Health Informatics Research, Manchester, UK

8. NIHR Manchester Biomedical Research Centre; Central Manchester University Hospitals NHS Foundation Trust; Manchester Academic Health Science Centre; Manchester

\section{Acknowledgements}

This project was funded by Arthritis Research UK (21226) and the National Institute for Health Research Collaboration for Leadership in Applied Health Research and Care (NIHR CLAHRC) Greater Manchester. Additional support was provided by the Arthritis Research UK Centre for Epidemiology (grant reference 20380). The NIHR CLAHRC Greater Manchester is a partnership between providers and commissioners from the NHS, industry and the third sector, as well as clinical and research staff from the University of Manchester. The views expressed are those of the authors and not necessarily those of the NIHR, the NHS or the Department of Health and Social Care.

\section{Publication and licensing}

Paper accepted for publication in the Journal of Health Organisation and Management, on 12 November 2020, DOI: 10.1108/JHOM-07-2020-0295. Full citation details are:

Sharp, C., Bresnen, M., Austin, L. and McCarthy, J., Dixon, W. and Sanders, C. (2020) Implementing disruptive technological change in UK healthcare: exploring development of a smart phone app for remote patient monitoring as a boundary object using qualitative methods. Journal of Health Organisation and Management, https://doi.org/10.1108/ihom-07-2020-0295

This AAM is deposited under the Creative Commons Attribution Non-commercial International Licence 4.0 (CC BY-NC 4.0) and any reuse is allowed in accordance with the terms outlined by the licence. To reuse the AAM for commercial purposes, permission should be sought by contacting permissions@emeraldinsight.com. 


\title{
Implementing disruptive technological change in UK healthcare: exploring development of a smart phone app for remote patient monitoring as a boundary object using qualitative methods
}

\begin{abstract}
Purpose: Developing technological innovations in healthcare is made complex and difficult due to effects upon the practices of professional, managerial and other stakeholders. Drawing upon the concept of boundary object, this paper explores the challenges of achieving effective collaboration in the development and use of a novel healthcare innovation in the English healthcare system.

Design: A case study is presented of the development and implementation of a smart phone application (app) for use by rheumatoid arthritis patients. Over a two-year period (2015-2017), qualitative data from recorded clinical consultations $(n=17)$, semistructured interviews $(n=52)$ and two focus groups $(n=13)$ were obtained from participants involved in the app's development and use (clinicians, patients, researchers, practitioners, IT specialists and managers).
\end{abstract}

Findings: The case focuses on the use of the app and its outputs as a system of interconnected boundary objects. The analysis highlights the challenges overcome in the innovation's development and how knowledge sharing between patients and clinicians was enhanced, altering the nature of the clinical consultation. It also shows how conditions surrounding the innovation both enabled its development and inhibited its wider scale up.

Originality: By recognizing that technological artefacts can simultaneously enable and inhibit collaboration, this paper highlights the need to overcome tensions between the transformative capability of such healthcare innovations and the inhibiting effects simultaneously created on change at a wider system level. 


\section{Implementing disruptive technological change in UK healthcare: exploring development of a smart phone app for remote patient monitoring as a boundary object using qualitative methods}

\section{Introduction}

The challenges and complexities associated with diffusing and implementing technological change in healthcare have been studied extensively (e.g. Damschroder et al., 2009; Greenhalgh et al., 2004, 2017; Barrett and Oborn, 2010; Mair et al., 2012; Petrakaki, 2014). Research consistently highlights not only the opportunities provided by innovations in technology - particularly those associated with information and communication technologies - but also the considerable difficulties involved in implementing and exploiting them in practice. This is due to the expected and unexpected challenges that arise in embedding them in organizational systems due to the disruptive effects they have upon professional and managerial practices (Lehouxa, 2012).

This paper is concerned with understanding further the complexities and challenges of technological change in the healthcare context. It focuses upon the development and application of new, disruptive forms of technological innovations associated with smartphone technology. The empirical case follows the development, implementation and use, in an English hospital, of a smartphone application (app) for rheumatoid arthritis (RA) patients. The app was designed to monitor patients' symptoms in real time and to integrate resultant data into their electronic health record (EHR) in graphical form, facilitating more targeted clinical consultations.

Rheumatoid arthritis is one of several long-term conditions which affect a quarter of the UK population and upon which the NHS long term plan places considerable 
emphasis (NHS, 2019). Between clinical consultations, patients manage their illness often with little interaction with healthcare services. The sporadic nature of clinical consultations means that clinicians are heavily reliant on potentially unreliable patient recall of events (Shiffman et al., 2008), along with more 'objective' measures such as clinical examination and blood test results. This makes rheumatoid arthritis a condition in which the availability of more information about the disease course between clinical visits might be valuable to both patients and clinicians. Apps for patients to track their RA symptoms do exist (Grainger et al., 2017), but these lack the functionality to pull data into clinical records. Studies using apps to integrate patient reported outcome data into the EHR have been conducted, but a recent review demonstrates the need for further understanding of the impact and effectiveness of these interventions (Gandrup et al., 2020). For clinicians, such data linkage might provide additional information about the patient's experience of the disease, above and beyond that which they are able to recall whilst under pressure in a time limited clinical consultation. For patients, it may provide insight into the nature and course of their illness, potentially empowering them to self-manage their illness with greater confidence. For the relationship between the two, it might enable greater mutual understanding, as well as help shape and improve clinical consultations.

The aim of the current study is to explore the development, adoption and implementation processes associated with such technology and how these affected the practices of professional, managerial and patient groups involved or implicated in the app's design, delivery and use. We explore the complex inter-relationships between these groups as they were mediated through the co-production of the technological object and the impact of its implementation upon their (changing) knowledge and practices. 
We do this by examining the app and the system of related objects involved in its development, as a set of boundary objects (Star and Griesemer, 1989). In brief, boundary objects assist individuals from different disciplines in translating or transforming knowledge and practice across disciplinary boundaries (Carlile, 2002). Our empirical analysis, which involved interviews, focus groups and recorded clinical consultations with key stakeholders, explores the integrative capabilities of the objects used and relations developed around them during their development (Nicolini et al., 2012; Scarbrough et al., 2015). It assesses the wider implications for understanding the challenges associated with embedding and diffusing new IT innovations within healthcare organizations.

\section{Technological innovation in healthcare and the role of boundary objects}

Research on technological change in healthcare has focused on the difficulties faced in implementing and embedding new forms of information and communication technology (Barrett and Oborn, 2010; Lehouxa, 2012; Petrakaki, 2014; Vest et al, 2019). Importantly, technological information systems not only help promote knowledge sharing and integration, they can also have disruptive effects on existing professional work, practices and domains (Motulsky, 2011; Petrakaki, 2012, 2014; Reich, 2012). This means that professional practices, norms and interests can be challenged and may need to be accommodated through the negotiation of interests (Constantinides and Barrett, 2006; Lehouxa, 2012). This inevitably creates considerable challenges for those attempting to implement such systems (Pols, 2011). Those challenges are magnified in healthcare, as they also involve bridging the 
clinician-patient interface, with all the complexities that brings for accommodating or attempting to transform patient and clinician behaviour (Mol, 2010; Oudshoorn, 2008).

As we will see, several important boundaries are implicated in the development and implementation of complex innovations such as this app (cf. Nicolini et al., 2012). To explore the impact of these boundaries and how they are mediated in this context, it is useful to draw upon a framework that puts socio-material conditions at the heart of the analysis. The concept of boundary objects (Star and Griesemer, 1989) is, again, of relevance, as it may be used to help understand how knowledge is created, shared and integrated across boundaries of practice between specialist groups involved in joint activity (Boland Jr et al., 2007; Boland Jr and Tenkasi, 1995; Carlile, 2002, 2004). Boundary objects can take many forms (material objects, documents, maps, presentations, etc.), but their shared defining characteristic is that they have some interpretative flexibility or 'plasticity' (Star and Griesemer, 1989). This allows different groups engaged in distributed practices to interact with one another and to engage in joint activity, whilst maintaining their individual perspectives, sharing or transforming their own knowledge and practices in the process (Carlile, 2002).

Information systems have long been viewed as boundary objects (Barrett and Oborn, 2010; Levina and Vaast, 2005), since their specification and development presupposes the need for knowledge sharing across boundaries (Ewenstein and Whyte, 2009) and their operation directly involves flows of information and knowledge between inter-connected communities of practice (Wenger, 1998). Recent research on technological innovations within healthcare has conceptualized technological artefacts as boundary objects (Smith, 2015; Swan et al., 2007), with stress being placed on the integrative potential of systems (Reed, 2016; Saario, 2012). Technological artefacts have also been shown to be important in connecting 
mainstream healthcare with complementary and alternative medicine (Keshet et al., 2013; Owens, 2015).

Despite this focus on integrative possibilities, much of the literature on boundary objects explores the capacity of innovations to reinforce professional boundaries and barriers to interaction (Allen, 2014; Hunter, 2014). The role that boundary objects play when they are designed with the aim of aiding collaboration has also been emphasized, including how they might evolve from being 'designated boundary objects' to 'boundary objects-in-use', integrated into everyday practice (Levina and Vaast, 2005).

Nicolini et al's (2012) case study of biomedical innovation makes an important contribution by proposing a three-level 'hierarchy' of objects, differentiating between tertiary objects (providing the physical, electronic or institutional infrastructure for collaboration); secondary objects (classic boundary objects as found in drawings, designs, etc.); and primary objects (which are more fundamental and epistemic in nature, helping inspire, motivate and sustain collaboration). They demonstrate how such objects have 'mutability', developing and changing in their role and use over time (e.g. from being an integrating idea that crystallizes into a more material object that helps further design and development collaboration) (see also Bresnen 2010; Nicolini, 2011). Scarbrough et al (2015) build upon this, emphasizing the relational qualities of how such systems of objects inter-connect and how collaboration and coordination is orchestrated through the complex (and evolving) links between them (ibid: 217-8).

An important further strand of research emphasizes how boundary objects are inscribed with relations of power (Oswick and Robertson, 2009; Thomas et al., 2008). As such, boundary objects can facilitate and inhibit knowledge sharing throughout the 
course of any interaction, since they are inscribed with meanings that shift as power dynamics and negotiations over their use unfold, enabling or hindering interaction, dependent upon their mobilization (Barrett and Oborn, 2010) and engagement by participants (Allen, 2014). Taken together, such recent work moves our understanding further away from regarding boundary objects as relatively stable and singular physical artefacts, emphasising instead their systemic inter-connectedness, multi-faceted nature and diverse effects on interaction. Moreover, it places centre stage how their use may be associated with the empowering or disempowering of particular groups and what that means for established professional and management practices.

In this paper, we present a more nuanced, situated and dynamic interpretation of interaction around technological systems as boundary objects in the healthcare context, exploring how they can simultaneously enable and hinder integration, through the recursive iterations and associated social interaction that occurs in their development, use and potential wider implementation. This points to the possibility that they may create tensions in their effects on particular groups and that these tensions may play out in ways that lead to the suppression and later activation of latent conflicts of interest or perspective - with implications for the stability, maintenance and generalizability of collaborative action centred around those particular objects. We explore the development, use and (prospects for) wider implementation and diffusion of a technological innovation, focusing particularly upon its evolving and changing role within a wider localized system of objects and relations amongst the multiple stakeholder groups involved. We examine how its interconnected components helped facilitate the crossing of three different types of boundary: that between the technical innovation's development and its use in practice; that between the illness management led by the patient at home and that planned in the clinic by patients and 
clinicians; and that between the implementation of the innovation into a single research clinic and wider scale up. Our analysis explores the role played by the inter-connected system of boundary objects in assisting (or inhibiting) integration, knowledge transformation and learning across these boundaries; the effects of changing knowledge and practices upon the different groups involved; and assesses the implications for the wider diffusion of such innovations across healthcare.

\section{Methods}

The research in this paper is case study based (Eisenhardt and Graebner, 2007) drawing on qualitative data collected from a range of stakeholders involved in the practical development, application and use of an Android smartphone app for selfmonitoring and reporting of RA symptoms by patients. The wider study, from which the qualitative data is derived, was undertaken over two-years (2015-2017) and was led by a multi-disciplinary steering group. A patient and public involvement group comprising six people with RA, met 13 times to feed into development of the app and provide information for the study.

The development of the app followed three phases: co-design of the app and its integration into the EHR; testing of the prototype for 4 weeks by a small number of patients; evaluation of feasibility and acceptability to patients over 85 days and evaluation of the app data's use during clinical consultations. Project managers liaised with a University-based software development team who developed the app, and with a hospital-based informatics team who integrated graphed patient reported outcomes into the EHR. The hospital hosting the research was a digitally mature site in the UK. 
Patients entered data into their app, daily, weekly and monthly. These data were available for patients to view themselves, and for clinicians and patients to view together in a graphed format within the EHR, alongside other more traditional data such as blood test results. Consultations followed a similar format to those in standard clinical practice, with additional dialogue taking place around the content of the graphs and what these might mean for patients' disease activity, and whether any changes to their clinical management was warranted. Further detail on the study design and app may be found elsewhere (Austin et al., 2019).

Sampling was purposive, aiming for maximum variation in gender, age and illness trajectory for patients, and a range of roles and expertise for IT staff, clinicians and researchers. Patients with rheumatoid arthritis were recruited from a local NHS Foundation Trust rheumatology department. Clinicians, managers and IT staff working on the project were recruited from the same Trust. In total, 52 semi-structured interviews (individual and small group), two focus groups (FGs) comprising 13 participants, and 17 clinical consultations were digitally audio-recorded and analyzed (see Table 1 for a summary of sources and the key to quotations used in the results section). Patients took part in either an interview or a FG during app development ('pre-app') and some took part in further interviews/FGs following implementation ('post-app'). Patients' demographics matched the general population of RA patients (age 32-84 years; time since RA diagnosis $<1>30$ years, 3:1 female to male).

[Table 1 about here] 
Three different data collection methods were used to ensure sufficient breadth and depth of data. Individual and small group interviews allowed in-depth exploration of participants' opinions and experiences of using the app (Patton, 2002). Focus group sessions with practitioners and IT staff captured the range of perspectives and allowed participants the opportunity to reflect upon and respond to others' opinions (Fitzpatrick and Boulton, 1994). They also generated data that directly reflected the context of interaction in the app's development and use. Clinical consultations enabled observation of the use of the app in real time. This was a crucial component because a key purpose of the app was to provide new data that could be used to inform treatment and management decisions. The nuances of how data were used in practice could not otherwise be captured via interviews alone.

Transcripts were analysed thematically drawing on a grounded theory approach (Glaser and Strauss, 1967). Initial inductive coding of data was conducted separately by three members of the research team, using NVivo. Comparison of emerging themes was made, with adjustments taking place via comments on descriptive accounts and discussions at team meetings. Having data from such a range of stakeholder groups allowed for triangulation of themes across data sources. Authors of this paper were members of the project team and clinician researchers participated in clinical consultations and contributed interview data. This close proximity allowed deeper insights to be drawn, but also prompted the need for care to be taken to ensure reflexivity during analysis. Non-clinical team members provided an additional check, as did triangulation of data. Once comparison of emerging themes had taken place, these were compared across the different data sets, including those pre-and postimplementation and refined, iteratively. 
The Greater Manchester Central Research Ethics Committee approved the study (ref. 15/NW/0172). All participants provided written informed consent prior to participation, with additional consent given for the recording of clinical consultations. All contributions were anonymized and held securely, according to University of Manchester guidelines.

\section{Results}

The data to be presented in this section highlight the ways in which developing the app and integrating it with clinical and hospital systems and practices reflected, reinforced or challenged different groups' interests and perspectives, generating tensions that needed effective handling. This was apparent in three main respects: in engaging users (patients) and supporting them in a more self-help approach; in attempting to embed novel data within existing clinical pathways, systems and practices; and in integrating data flows associated with a bespoke system with the wider standardized hospital IT system. Important implications thus emerge from the following analysis for clinical practice and patient engagement, innovation diffusion in practice, and the generalizability of the app-based system to other disease areas and healthcare organizations.

\subsection{Boundary between technical innovation and clinical practice}

The boundary between innovation and practice was navigated during the innovation's development and integration. Unless it fulfilled the needs of its two key stakeholders (patients and clinicians), its future would be lost before its implementation had begun. The research team proposed the initial design of the innovation, upon which patients 
commented. Patients' preference was to enter data only when something notable happened; practitioners preferred daily data capture. Patients wished to use the app to identify factors influencing their illness and proposed using it as a 'confidante'. Different user requirements and the potential tensions arising were mediated through compromise in app design: patients were willing to input data more regularly if reminder functions were incorporated; and a free-text diary function was introduced.

Disciplinary differences within the project management team and resulting boundaries between stakeholder groups had the potential to impede progress, particularly between software developers and hospital IT staff:

[IT6]: It's very typical in that sense, from a starting point of them not knowing the EHR that way. Or us not knowing what they're going to do. Trying to work a way to what is this really going to look like and, generally, the scope expands.

To overcome this, clarity of roles within the team was felt to be important:

[IT 13]: There's two different worlds and it's difficult to know from people's job titles and things who I needed to speak to.

IT staff reported frustrations in clarifying the specification, particularly early on, given the very different expectations and approaches across groups. Importantly, IT specialists needed to be able to make sense of work on the app as a project. Once projectified in that way - and establishing clear roles and specification formed an important part of that - it was easier for them to incorporate the work in their routines and to respond to the needs of other groups. The project team used other techniques, including brokering roles and shared documents, to bridge inter-disciplinary 
boundaries. Members of the research team, who might otherwise have been seen as 'external' to IT staff, were embedded within the project:

[IT5]: Because people were aware of what [the healthcare research organization] was in IT, because we've dealt with them before, we've done other projects. So that visibility was there. It wasn't like it was an outside, third party person coming in saying: 'I want this.' It was somebody that was perceived as working here.

Team members reported different experiences regarding establishment of a shared drive for information-sharing with some finding it useful, while others reported that it was limited because it was not kept up to date:

[IT5]: On other projects, between organizations, it's been quite hard to have one place where people can see. But this Google Document thing just got rid of that issue, and everybody could log onto it. They could change it, they could see it. They knew who was doing what. Everybody's number was on there.

[IT12]: there was a spread sheet that was produced which was to act as the one true statement of [work needed and done] ... But that wasn't necessarily kept upto-date. That was also a weakness. So clear specification and then keeping the specification document up-to-date.

Viewing this shared drive as a boundary object (a standardized form, according to Star's original definition (Star and Griesemer, 1989)) allows us to view its failure to retain its function when not maintained as resonating with Levina and Vaast's (2005) argument that designated boundary objects fail to become boundary objects-in-use when they are not incorporated into every day practice. Overall, though, the different 
requirements of patients and practitioners were successfully mediated and clarity of role and product specification were regarded as key to enabling successful collaboration. The app itself served as a primary boundary object (Nicolini et al., 2012), both inspiring and helping sustain the collaboration.

\subsection{Boundary between disease management at home and that in the clinic} Next, we consider how participants felt that the app enhanced patients' selfmanagement, acting as a boundary object at home and, through the graphics, mediating between patients and clinicians during consultations.

\subsubsection{The app as a boundary object}

Patients hold responsibility for 'self-management' between clinic visits. Data from interviews with patients, clinicians and managers, and recorded consultations, showed that the app was felt to have the potential to enhance patient self-management. However, the extent to which the app benefitted patients and their relationships with family was an unexpected finding, and testament to its impact. Patients reported that using the app (especially the diary function for which they had campaigned during the design phase) enabled them to identify and avoid potential triggers for flares, which they could then report to their clinicians.

[Pt2]: If I hadn't have had the diary aspect, I might have remembered that l'd had a bad couple of days. But I probably wouldn't have remembered that l'd been poorly for a few days with a really bad cold, leading up to that.

Patients explained how they used their app data at home to mediate the boundary between themselves and their relatives. In sharing this data, patients felt better 
understood without needing to give lengthy explanations or justifications for how they were feeling. By relieving patients of the burden of trying to explain their symptoms, and enabling relatives to gain a more complete picture of their condition, this provided a compelling example of the app creating shared understanding and transforming knowledge and promoting learning (Carlile, 2002). A minority of patients and practitioners did, however, note that the app might worsen anxiety, which is in line with findings on other health technology interventions (Brunton et al., 2015).

Some patients found reducing their illness to scores problematic. In contrast, clinicians are heavily reliant on scoring systems in order to access expensive treatment, revealing a tension between the clinician's need for this 'objective evidence' and oversimplification as perceived by patients. In this respect, the scoring system that was integral to the app, and which was necessary to support the graphing function, had its limitations. Nevertheless, its plasticity did enable the translation of patient symptoms into clinical data that fed into doctor-patient interactions.

\subsubsection{The graphs as boundary objects}

Graphical data from the app provided a detailed account of disease activity between consultations. Patients expressed delight at seeing 'their' data appear in graphical format on the clinicians' screen - the appearance outside their smartphone and in their electronic record, for some, made it seem more official, validating it.

CONSULTATION:

[Dr2]: So, I've had a look through the results, let me just turn the screen around so you can see it as well. So those results that you have get sent into the record and then we can make graphs of it. 
[Pt24]: What, you've got them already here?

[Dr2]: Yeah, so I've got them there, I can see them. I've seen them already, so I'm asking you these questions knowing the answer to some of them. [Pt24]: I didn't realize that they'd come through...

Practitioners who were interviewed prior to the app's development felt that it would lead to more shared decision making:

[R1]: [It] encourages more of that kind of collaborative effort and managing their symptoms. You look back and say like well before you started on Methotrexate, this is what your disease was like, and not just have like a one-off figure to show them.

The graphs effectively translated data from daily life into something more meaningful. Patients reported that it removed the burden of communicating their illness to the clinician, not only creating shared meaning across the clinician/patient semantic boundary, but also transforming patients' lived experiences into something easily understood by clinicians and acting as a mediator across this pragmatic boundary (Carlile, 2002).

[Pt8]: [Dr1] showed me the graph and you could see where it had shot up and then it sort of did that. So you could actually see it, which clarifies it, but clarifies it also for the person looking at it; because they can see rather than saying, oh well, how did you feel? [...] It's a real tool to be able to show somebody else what you are going through.

Clinicians were familiar with viewing blood test results in the same graphical format and incorporated the task of checking the graphs into their usual routine, during which 
they compared data with patients' responses, probing further if inconsistencies were apparent.

CONSULTATION:

[Dr1]: ... in all of your graphs, there's a, kind of, peak between August and September in the same place...I suspect there's something happened to you through, sort of, the latter half of August...

[Pt23]: Right. I'm trying to think what that would be [...] I know, end of August. Tell you where I went then, I went to Edinburgh ... We went to The Fringe [festival] for a couple of days, which is fantastic but I over did it. I'll be honest. I did.

Clinicians felt that the graphs enhanced their own communication, consolidating their clinical opinion with 'evidence' from the patients' graphs. This worked with regard to treatment interventions and with more interpersonal aspects of the relationship:

[Dr1] She was very stoical, and some people you can tell they're stoical [...] But her charts did show a number of peaks and I said to her actually, you're telling me you've been fine but these are suggesting that you've been less fine. And then we had quite an open conversation .... So, it was quite nice to be able to have that with some evidence to say look, you're not fine, this is telling me you're not fine.

This section demonstrates the transformation of practice on the part of clinicians, who used the graphs to engage more effectively with the patient and their lived experience. Not only did the graphs facilitate communication between clinician and patient, but the nature of the consultation also changed, as the two groups shared the data and genuine dialogue took place: 
CONSULTATION:

[Dr1]: And so, you are right that there is quite a significant sort of day to day fluctuation so that is three out of ten down here and that is seven out of ten up here...

[Pt12]: It's funny on this, you can see the trend can't you?

[Dr1]: Yes, absolutely.

Clinicians reported that patients responded well to the graphs; that they assisted in the discussion of other results (e.g. blood tests); and turned the computer into a shared tool. Both groups reported that having this kind of contemporaneous data provided learning opportunities. For example, demonstrating the impact of a simple intervention (e.g. providing compression gloves) or noting gradual trends in improvement in response to a medication could help persuade both patients and clinicians alike of their utility:

[Dr2]: her pain graph got much better, as did her coping ... and clearly her whole life was transformed by this intervention. That taught me the extent to which such interventions are useful

Clinicians reported that graphical representation of some of the traditionally less welladdressed features of RA (e.g. low mood, fatigue, sleep), raised their profile and provided a deeper understanding of the impact of disease flares, stimulating them to open up the consultation to these issues. In tandem, patients felt empowered to discuss issues that they might otherwise have felt disinclined to raise. 


\subsubsection{Interconnected boundary objects}

This section has demonstrated how different aspects of the innovation acted as secondary boundary objects between the illness management taking place at home and that planned in clinic (Nicolini et al., 2012). The app increased patient awareness of their illness and helped them share their disease activity with relations at home. In the clinic, the graphs enhanced knowledge sharing, changed the nature of the consultation, and contributed to new learning on both sides. These examples demonstrate how the app and the graphs, as discrete aspects of the innovation, acted as interconnected boundary objects (Scarbrough et al., 2015), aiding collaboration. This collaboration occurred in expected ways (better communication, the primary technical goal of the app) and unexpected ways (teaching each party the relative merit of certain interventions, and providing a clearer understanding of the other's perspective).

\subsection{Boundary between the implementation of the innovation from a single research clinic to wider scale up}

This final section examines the prospects and challenges faced in moving from localized adoption of the innovation during this study, to adoption at scale. Three areas emerged as important enabling and inhibiting conditions: individual and relational capabilities, resourcing and technical infrastructure.

\subsubsection{Individual and relational capabilities}

Considerable effort in building close working relationships and championing the initiative with key stakeholders was involved in developing and testing the innovation. 
IT specialists and managers shared the view that building upon the relationships formed during the app's development increased the chances of successful scale-up.

[M2]: ... really important would be clinical engagement and local champions ... But again, I suppose ultimately it would be local networks of like-minded colleagues who'd try and implement on other sites.

Similarly, a good situational understanding of how the innovation connected with local practice was highlighted as essential:

[IT12]: I think there's no substitute for experience in terms of having experience with working on these kind of research projects integrating with NHS systems. I think for just any old app developer coming along I doubt that they could pick up a toolkit and suddenly know everything they needed to know about how to make this work. It's quite specialist really.

In considering scale up, managers acknowledged the role of early adopters. Clinicians felt that the innovation's benefits outweighed the burden of time taken to use it, which would enhance the likelihood of any future uptake (we recognize that the clinicians in this study were likely to view the innovation favourably). That patients expressed concern that some clinicians might not engage with the innovation highlighted a tension between theirs and clinicians' perpsectives of this intervention (Brunton et al., 2015; Deering et al., 2013).

[P15] I don't know about [original rheumatologist] because I think he was old school [...] Yeah, I don't think he would have appreciated a mobile phone.

Some managers felt that patients championing the app would improve wider uptake. Clinicians and patients questioned whether or not patients would remain engaged 
longer-term, particularly those with stable disease who had less to gain from entering data regularly, mirroring concerns expressed by patients prior to the study.

Clinician researchers suggested that healthcare professionals could become overly reliant on the app data, forfeiting a thorough history in favour of dependence upon the graphs. They were concerned that patients who did not engage with the app might be penalized for a new form of 'non-adherence' (a failure to comply with suggested treatment plans). Neither of these concerns played out in this study. But, they highlight potential inhibiting factors related to the latent capabilities of the innovation and how these may surface when translated into other clinician-patient settings.

\subsubsection{Resources}

Patients, clinicians and managers all viewed the innovation as having the potential to tailor appointment scheduling. Patients and clinicians shared concern about the logistics involved, and where responsibility for triggering an episode of care would lie. Managers were more concerned with the resourcing aspects of this potential development. The interactions with app data required for triaging appointments would not be accounted for under the current system and so scale up would require changes in commissioning practice. A potential increase in patient anxiety leading to a potential rise in consultation rates was a further concern for managers. Despite this, they were broadly in favour if the innovation would save resources:

[M3]: Everything else is focused on cost and efficiency at the moment, and the driver for anything like this, the largest driver will be efficiency. So if we can follow up patients more efficiently that's going to be very attractive. 
Finally, maintaining the system once the innovation had been adopted and embedded raised issues regarding funding and personnel.

[IT9]: It comes back to how well can it be supported? Do we have the resources to do that? What would be the maintenance overhead? You know, is there any capital cost attached to it in terms of how long a life we can expect from this app and what do you do then for revisions?

\subsubsection{Technical infrastructure}

IT staff and managers acknowledged that introducing the innovation to a 'digitally mature organisation' was key to the venture's success.

[IT6]: The issues you'll have will be the level of digital maturity ... Technology is the same pretty much wherever you go across the world. The challenge would be whether their E[H]Rs are mature enough to be able to do the sort of things that you want to do, whether they have that capability within the interface team.

Managers' views were the more muted of the two, with digital maturity being 'nice to have' rather than being a pre-requisite for organisational success. Stakeholders identified a need to ensure that the app and associated infrastructure were as generic as possible. Standardized processes were felt to enhance the potential to integrate with different IT systems, highlighting a real tension as boundary conditions varied between the project and IT systems.

[IT6]: I can get my interface people to build an interface that will gather the pathology from each trust, but each one of those interfaces will be a pointto-point connection. It will be a bespoke development and a lengthy 
development as well ... But if everyone fed their information into a centralised port then we could all take it out ... Standardized way of working will enable us to move at a much faster rate.

At the same time, the need to have the capability to incorporate more ad hoc interfaces was recognized:

[M2]: What we need to be doing as a trust ... is making sure that those interfaces and interoperability is in the right place for devices such as [innovation] to interact with us. So we have an obligation, if you like, as a provider trust to try and move our infrastructure towards being compatible with those.

IT staff identified that development by software developers working independently from the EHR team put their compatibility following future updates at risk.

[M2] So I know that with [the app] I think a specific interface has been built into the electronic patient record. But from the middle of next year with our $E[H] R$ upgrade we're looking at [compatibility] so that these devices can talk to us more reliably ... At the minute the interface is unreliable. Where there are upgrades to the $E[H] R$ it can become technically more difficult to reformat that upgrade.

In other words, the localized development of the app had been what had galvanized interest and was made possible through a logic of a bespoke design that flexibly met specific patient group and diagnostic needs. But the real value in widening that out (to other hospitals, other disease areas) required an approach that reflected a logic of standardization and efficiency. That the study developed an isolated research innovation rather than a longer term programme of development was identified earlier 
as a form of projectification that had served the initial development of the app well. However, such projectification was now insufficient for, or even potentially inhibiting of, its wider roll out.

[IT13]: For us, [the app] is a short term project. There's been no mention of turning it into a product as it were. It's a research tool. If you wanted to turn it into a product then, yes, you need people to regularly update components, make sure it still works on the new smartphones and what have you. There's no easy silver bullet for that one.

This third and final section of the analysis has highlighted three sets of boundary conditions affecting the successful scale up of this innovation. These enabling and inhibiting conditions - individual and relational capabilities, resources and technical infrastructure - represented important tertiary level conditions that related to the wider infrastructure with which, ultimately, the app needed to interconnect. The transformation of knowledge and practice that was so central during the development and testing of the app paradoxically created conditions whose replication was necessary - but potentially more challenging - if the innovation was to diffuse more widely.

\section{Discussion}

There has been a growing literature focused on implementation of technologies in healthcare, and multiple theoretical frameworks have evolved to explain and evaluate such complex interventions, including remote monitoring (Dramschroder et al, 2009; Greenhalgh et al, 2004; Greenhalgh et al, 2017; May et al, 2009). Such frameworks draw attention to complex processes, mechanisms and interactions that shape 
implementation and adoption (or failure) within healthcare contexts. Studies focusing on implementation of new IT systems and tools have described the role of organisational environments (Gude et al, 2019; Vest et al, 2019) and front line leaders (Ross et al, 2018; Kujala et al, 2019) as crucial to diffusion and adoption. Whilst there has been some focus on roles and interactions of professionals and patients associated with digital innovations, there has been a predominant emphasis on the workability of systems, with less attention paid to micro-interactions at the centre of technological change (Mair et al, 2012). Others have highlighted the need for theoretically informative implementation research to develop new empirical insights (Kislov et al, 2019). In this study, we have utilised the concept of boundary object to illuminate the interactional and organisational contexts shaping development of this new innovation within implications for adoption and change.

Indeed, analysis of the development, use and prospective generalization of the interconnected parts of this innovation, including the app and associated graphs, threw up a number of important conceptual and practical implications. First, its development across the boundary between innovation and practice can be seen both as a technical achievement and an ongoing social accomplishment. The object created a focus around which professional communities with quite distinct purposes, practices and perspectives worked, developing and deploying a common tool to achieve a common purpose (cf. Nicolini et al (2012). Artefacts in use during the development process, such as the shared-drive, required regular updating in order to fulfil their potential as a boundary object-in-use (Levina and Vaast, 2005). The case demonstrated the importance of clarity of project specification and of personal roles, in enabling effective cooperation across distinct communities. As a primary object around which these communities, working towards the shared purpose of app development coalesced, the 
innovation itself was not sufficient to enable them to accomplish this goal, with the need for project team members to act as brokers emerging, echoing Sapsed and Salter's (2004) observation that boundary objects cannot function without human interaction.

Second, making the system work at a local level was challenging since the app inevitably contained within it certain prescriptions that, while they had normative value in promoting a common purpose (e.g. meeting patients' needs), also potentially conflicted with existing system and organizational imperatives (important for the efficiency of healthcare delivery), and with the current model of clinical care (Deering et al., 2013). This ensured that the project required continuing action not simply to explain and justify any technical, clinical or administrative accommodations required, but also to sustain the coalition of interests involved in its design and implementation. Aspects of the innovation really came to light as boundary objects-in-use in their role in bridging boundaries between patients and their relatives (through the app), and with healthcare professionals (through the graphs) (Levina and Vaast, 2005). That these two linked aspects of the innovation worked together as boundary objects is redolent of Scarbrough's (2015) findings on the systemic interconnectedness of boundary objects. We demonstrated how, through transforming the nature of the consultation, it also unsettled normalized relations of power (Mørk et al., 2010). It challenged systems of generalized care and standardized information flows and, by providing patients with evidence to enable them to communicate more effectively with clinicians, it shifted the power dynamics within the consultation. Similarly, it enabled clinicians to address different aspects of patients' care and to use the innovation to communicate their perspective more effectively. Use of the innovation as a boundary object facilitating knowledge exchange in two directions was unexpected in that it improved 
communication between patients and clinicians by disrupting existing clinical diagnostic and treatment practices, resulting in more patient-centred care. This use of the innovation to cross such a complex pragmatic boundary (Carlile, 2002) was not dissimilar to Nicolini et al's (2012) depiction of the effects of secondary boundary objects in enabling collaboration and learning between groups.

Lastly, the innovation provided a joint learning opportunity. Patients learned about triggers for disease fluctuations and clinicians learned about the impact of interventions and the value in addressing 'non-clinical' topics. The obvious challenge for this, with implications for taking the project forward, is that what was seen here as patient empowerment could elsewhere perhaps be interpreted as more of a challenge to traditional, paternalistic models of clinical consultation (Deering et al., 2013). As such, its more disruptive effects were both a sine qua non of its development and application, but also a potential barrier to its wider diffusion. While such challenges might be manageable at a local level given the strength of local relationships and commitments demonstrated in our findings, extrapolating that to other contexts, transgressing the boundary between implementation of the app to wider scale up could be more difficult. On a wider canvas, there could be significant challenges to existing power/knowledge configurations that the roll out of the initiative would surface, notwithstanding the greater general emphasis now put on patient involvement and choice (cf. Newell (2003). As well as the direct impact upon established clinical professional practice noted above, we identified challenges to the long-term sustainability and scaling up of this innovation at a tertiary level (Nicolini et al., 2012) associated with three sets of infrastructural conditions - namely, individual and relational capabilities, resources and technical infrastructure. 
The importance of strong clinical leadership and the need to build upon existing networks and relationships were considered key to attempts to scale up the innovation. Managers in particular noted that organizational change would be required with regard to commissioning, and all stakeholders expressed concern about the resource implications of sustaining the innovation. The characteristics of both patients and clinicians within this study mean that they were likely to view such an innovation favourably. We recognize this caveat and the implication that, outwith this research environment, such an innovation would likely be met by a broader range of opinions and capabilities. The potential for 'non-adherence' exists, with less engaged patient groups perhaps being less likely to engage with 'prescribed' innovations. Participants stressed that creating and utilizing generalizable and generic IT infrastructure would enhance the chances of attempts to scale up the project. While this may help enable commitment and compliance, it is unlikely however, to match the level of engagement and interest centred upon a more bespoke development such as this particular innovation.

With regard to technological capabilities, we noted that the focal hospital is an early adopter of information technology development and that the availability of external research funding meant that undertaking this particular project was prioritized by busy IT staff. In addition, the digital maturity of the host allowed for the integration of the graphical data directly into the EHR, which has been noted elsewhere as a 'critical success factor' (Tang et al., 2003). These factors acted as facilitators in our case and make the prospect of scaling it up to other, less digitally mature organizations with fewer financial resources, clearly more challenging.

The overall implication is that boundary objects as the integral parts of this innovation may have powerful integrative effects at certain points or stages in both its 
development and use. It is important to see the development of the object as embedded within, and inevitably shaped by, the (shifting) constellation of social interests, relations and perspectives brought by each community of practice to the project. This of course has implications too for wider attempts to reconcile the embedding of new (technical) initiatives in local practice with the need to generalize new knowledge and learning gained from (technical) innovations across the sector. However, it may also suppress key differences in interest and perspective whose latent disruptive effects may emerge at other points or stages in the developmental or implementation process, to inhibit further development or wider application (cf. (Barrett and Oborn, 2010)).

\section{Conclusion}

In this paper, we have used the concept of boundary object to explore processes of collaboration, knowledge transformation and learning associated with the development, use and potential diffusion of a specific healthcare innovation, codeveloped by clinical researchers with their patients. The use of boundary object theory to interrogate the development of technological innovations (Barrett and Oborn, 2010; Levina and Vaast, 2005; Swan et al., 2007) and to understand the mediation of relationships between healthcare professionals (Allen, 2014; Keshet et al., 2013) has been explored previously and is not in itself new. However, in charting both the development and shaping of this innovation over time and in exploring the development of the inter-connected parts of this object as they became (re-)positioned as boundary objects-in-use, the work has built on recent attempts to understand the development of technological artefacts situated in systems of inter-connected objects 
and relations (Nicolini et al., 2012; Scarbrough et al., 2015). Specifically, it has demonstrated how the integrative and learning potential associated with such innovations in their (co-)development and use (cf. (Carlile, 2002, 2004) paradoxically also inhibits the (potential) application and diffusion of such technology on a wider scale. As such, the integrative and relational capabilities they bring to the generation of new knowledge and practice also constitute the diffusion challenges they subsequently confront.

The study has been an exploratory one of a particular app development focused upon one type of clinical condition based in one particular clinical setting and drawing upon a relatively small group of participants. As such, there is more work needed on understanding the enablers and barriers to developing and diffusing such applications across a wider range of patient groups and organisational settings. As already suggested, much may depend upon factors such as the digital maturity of the clinical setting, the demographic characteristics of particular patient groups, the nature of particular conditions, and the professional orientations of clinicians.

Neverthess, the findings have obvious wider implications for the diffusion of technological innovations in as complex a setting as healthcare. It suggests a major challenge in the generalized diffusion of new innovations when the impetus behind them is situated in the localized conditions that ensure their immediate success. However, it also points to very specific set of conditions surrounding clearly identifiable boundaries of practice that both inhibit and enable the wider development and diffusion of such innovations. It is by recognizing and intensifying effort to bridge those boundaries of practice and to confront or circumvent those conditions that wider lessons can be drawn about overcoming barriers to diffusion that might otherwise seem problematic, or even unsurmountable. 
As such, the research has a number of important practical implications. These include recognizing: the integrative potential of such technological innovations in bringing together key stakeholders and bridging boundaries of practice; the importance of strong clinical leadership and capitalizing on existing networks and relationships; the benefits (intended and unintended) of the remote monitoring tool for patient selfmanagement and empowerment; and, perhaps most significantly, the importance of local, organisational conditions in facilitating or inhibiting the scale up of such innovations.

\section{References}

Allen, D., 2014. Lost in translation? 'Evidence'and the articulation of institutional logics in integrated care pathways: from positive to negative boundary object? Sociology of health \& illness 36, 807-822.

Austin L, Sharp CA, Van Der Veer S, Machin M, Humphreys J, Mellor P, Mccarthy J, Ainsworth J, Sanders C, Dixon W, 2019. Providing "the bigger picture": benefits and feasibility of integrating remote monitoring from smartphones into the electronic health record. Rheumatology, kez207, https://doi.org/10.1093/rheumatology/kez207

Barrett, M., Oborn, E., 2010. Boundary object use in cross-cultural software development teams. Human Relations 63, 1199-1221.

Boland Jr, R.J., Lyytinen, K., Yoo, Y., 2007. Wakes of innovation in project networks: The case of digital 3-D representations in architecture, engineering, and construction. Organization Science 18, 631-647.

Boland Jr, R.J., Tenkasi, R.V., 1995. Perspective making and perspective taking in communities of knowing. Organization Science 6, 350-372.

Bresnen, M., 2010. Keeping it real? Constituting partnering through boundary objects. Construction Management and Economics 28, 615-628.

Brunton, L., Bower, P., Sanders, C., 2015. The Contradictions of Telehealth User Experience in Chronic Obstructive Pulmonary Disease (COPD): A Qualitative MetaSynthesis. PLoS ONE 10, e0139561.

Carlile, P.R., 2002. A pragmatic view of knowledge and boundaries: Boundary objects in new product development. Organization Science 13, 442-455.

Carlile, P.R., 2004. Transferring, translating, and transforming: An integrative framework for managing knowledge across boundaries. Organization Science 15, 555568. 
Constantinides, P., Barrett, M., 2006. Negotiating ICT development and use: The case of a telemedicine system in the healthcare region of Crete. Information and Organization 16, 27-55.

Damschroder L, Aron D, Keith R, Kirsh S, Alexander J, Lowery J. 2009. Fostering implementation of health services research findings into practice: a consolidated framework for advancing implementation science. Impl Sci. 4:50. doi: 10.1.1186/17485908-4-50.

Deering, M.J., Siminerio, E., Weinstein, S., 2013. Issue brief: Patient-generated health data and health IT. Office of the National Coordinator for Health Information Technology, 1-11.

Eisenhardt, K.M., Graebner, M.E., 2007. Theory building from cases: Opportunities and challenges. Academy of management journal 50, 25-32.

Ewenstein, B., Whyte, J., 2009. Knowledge practices in design: the role of visual representations asepistemic objects'. Organization Studies 30, 07-30.

Fitzpatrick, R., Boulton, M. 1994. Qualitative methods for assessing health care. Quality in Health Care, 3(2), 107-113.

Gandrup, J., Ali, S. M., McBeth, J., van der Veer, S.N., Dixon, W.G. (2020) Remote symptom monitoring integrated into electronic health records: A systematic review, Journal of the American Medical Informatics Association, , ocaa177, https://doi.org/10.1093/jamia/ocaa177

Glaser, A., Strauss, A.L., 1967. The discovery of grounded theory. Aldine, Chicago.

Grainger, R., Townsley, H., White, B., Langlotz, T., Taylor, W.J. 2017. JMIR mHealth uHealth. 5, e7).

Greenhalgh T, Robert G, Macfarlane F, Bate P, Kyriakidou 0. 2004. Diffusion of innovations in service organizations: systematic review and recommendations. Milbank Q. 82: 4: 581-629.

Greenhalgh T, Wherton J, Papoutsi C, Lynch J, Hughes G, A'Court C, Hinder S, Fahy N, Proctor R, Shaw S. 2017. Beyond adoption: A new framework for theorizing and evaluating nonadoption, abandonment, and challenges to the scale-up, spread and sustainability of health and care technologies. Jnl Med Internet Res. 19: 11: e367

Hunter, B., Segrott, J. , 2014. Renegotiating inter-professional boundaries in maternity care: implementing a clinical pathway for normal labour. Sociology of health \& illness 36(5), 719-737.

Keshet, Y., Ben - Arye, E., Schiff, E., 2013. The use of boundary objects to enhance interprofessional collaboration: integrating complementary medicine in a hospital setting. Sociology of health \& illness 35, 666-681.

Kujala S, Horhammer I, Heponiemi T, Josefsson K. 2019. The role of frontline leaders in building health professional support for a new patient portal: survey study, Journal of Medical Internet Research, 21, 3, e11413 https://www.jmir.org/2019/3/e11413/

Lehouxa, P., Sicottea, C., Denisa, J-L., Bergb, M., Lacroix, A. , 2012. The theory of use behind telemedicine: how compatible with physicians' clinical routines? Social science \& medicine 54, 889-904. 
Levina, N., Vaast, E., 2005. The emergence of boundary spanning competence in practice: implications for implementation and use of information systems. MIS quarterly, 335-363.

Mair F, May C, O’Donnell, Finch T, Sullivan F, Murray E. 2012. Factors that promote or inhibit the implementation of e-health systems: an explanatory systematic reviews. Bull WHO. 90: 5: 357-64

May C, Mair F, Finch T, McFarlane A, Dowrick C, Treweek S, Rapley T, Ballini L, Ong BN, Rogers A, Murray E, Elwyn G, Légaré F, Gunn J, Montori V. 2009. Development of a theory of implementation and integration: Normalization Process Theory. Impl Sci. 4: 29. doi: 10.1186/1748-5908-4-29

Mol, A., Moser, I. and Pols, J. , 2010. Care in Practice: On Tinkering in Clinics, Homes and Farms.

Mørk, B.E., Hoholm, T., Ellingsen, G., Edwin, B., Aanestad, M., 2010. Challenging expertise: On power relations within and across communities of practice in medical innovation. Management Learning 41, 575-592.

Motulsky, A., Sicotte, C., Lamothe, L., Winslade, N., Tamblyn, R., 2011. Electronic prescriptions and disruptions to the jurisdiction of community pharmacists. Social science \& medicine $73,121-128$.

Newell, S., Edelman, L., Scarbrough, H., Swan, J., Bresnen, M. , 2003. “Best practice” development and transfer in the NHS: the importance of process as well as product knowledge. Health Services Management Research 16(1), 1-12.

Nicolini, D., 2011. Practice as the site of knowing: Insights from the field of telemedicine. Organization Science 22, 602-620.

Nicolini, D., Mengis, J., Swan, J., 2012. Understanding the role of objects in crossdisciplinary collaboration. Organization Science 23, 612-629.

NHS, 2019. The NHS Long Term Plan, Version 1.2, August 2019, https://www.longtermplan.nhs.uk/wp-content/uploads/2019/08/nhs-long-term-planversion-1.2.pdf ( 8 October 2020, date last accessed)

Oswick, C., Robertson, M., 2009. Boundary objects reconsidered: from bridges and anchors to barricades and mazes. Journal of Change Management 9, 179-193.

Oudshoorn, N., 2008. Diagnosis at a distance: the invisible work of patients and healthcare professionals in cardiac telemonitoring technology. Sociology of health \& illness 30(2), 272-288.

Owens, K., 2015. Boundary objects in complementary and alternative medicine: acupuncture vs Christian Science. Social science \& medicine 128, 18-24.

Patton, M. Q. 2002. Qualitative Research \& Evaluation Methods, London, Sage.

Petrakaki, D., Barber, N., Waring, J. , 2012. The possibilities of technology in shaping healthcare professionals: (Re/de-)professionalization of pharmacists in England. Social science \& medicine 75, 429-437.

Petrakaki, D., Waring, J., Barber, N. , 2014. Technological affordances of risk and blame: the case of the electronic prescription service in England. Sociology of health \& illness 36(5), 703-718. 
Pols, J., Willems, D. , 2011. Innovation and evaluation: taming and unleashing telecare technology. Sociology of health \& illness 33(3), 484-498.

Reed, K., Kochetkova, I., Molyneux-Hodgson, S., 2016. 'You're looking for different parts in a jigsaw': foetal MRI as an emerging technology in professional practice Sociology of health \& illness 38(5), 736-752.

Reich, A., 2012. Disciplined doctors: the electronic medical record and physicians' changing relationship to medical knowledge. Social science \& medicine 74, 1021-1028.

Saario, S., Hall, C., Peckover, S. , 2012. Inter-professional electronic documents and child health: a study of persisting non-electronic communication in the use of electronic documents. Social Science \& Medicine, 75(12), 2207-2214.

Sapsed, J., Salter, A., 2004. Postcards from the edge: local communities, global programs and boundary objects. Organization Studies 25, 1515-1534.

Scarbrough, H., Panourgias, N.S., Nandhakumar, J., 2015. Developing a Relational View of the Organizing Role of Objects: A study of the innovation process in computer games. Organization Studies 36, 197-220.

Shiffman, S., Stone, A.A., Hufford, M.R., 2008. Ecological momentary assessment. Annu. Rev. Clin. Psychol. 4, 1-32.

Smith, S., Ward, V. , 2015. The role of boundary maintenance and blurring in a UK collaborative research project: how researchers and health services managers made sense of new ways of working Social science \& medicine 130, 225-233.

Star, S.L., Griesemer, J.R., 1989. Institutional ecology,translations' and boundary objects: Amateurs and professionals in Berkeley's Museum of Vertebrate Zoology, 1907-39. Social studies of science 19, 387-420.

Swan, J., Bresnen, M., Newell, S., Robertson, M., 2007. The object of knowledge: the role of objects in biomedical innovation. Human Relations 60, 1809-1837.

Tang, P.C., Black, W., Buchanan, J., Young, C.Y., Hooper, D., Lane, S.R., Love, B., Mitchell, C., Smith, N., Turnbull, J.R., 2003. PAMFOnline: integrating EHealth with an electronic medical record system, AMIA Annual Symposium Proceedings. American Medical Informatics Association, p. 644.

Thomas, R., Sargent, L.D., Hardy, C., 2008. Power and participation in the production of boundary objects. Cardiff Human Resource Management Working Papers. .

Vest JR, Jung HY, Wiley K, Kooreman MA, Pettit L, \& Unruh MA 2019 Adoption of Health Information Technology Among US Nursing Facilities, Journal of the American Medical Directors Association, 20, 8: 995-1000.

Wenger, E., 1998. Communities of practice: Learning, meaning, and identity.

\section{Cambridge university press.}


Table 1 Summary of data sources

\begin{tabular}{|c|c|}
\hline $\begin{array}{l}\text { Stakeholder (number): key to } \\
\text { quotes }\end{array}$ & Interactions \\
\hline \multicolumn{2}{|l|}{ PRE APP } \\
\hline Patient $(n=18): P t$ & $\begin{array}{l}4 \text { interviews } \\
6 \text { small group interviews }(3,3,2,2,2,2 \\
\text { participants respectively) }\end{array}$ \\
\hline Practitioner $(n=10): P r$ & $\begin{array}{l}3 \text { interviews } \\
1 \text { focus group ( } 4 \text { consultants, } 3 \text { specialty trainees) }\end{array}$ \\
\hline Researcher $(n=10): R$ & 10 interviews \\
\hline IT specialist $(n=7)$ : IT & $\begin{array}{l}1 \text { interview } \\
1 \text { focus group ( } 6 \text { participants) }\end{array}$ \\
\hline Manager $(n=6)$ : M & 6 interviews \\
\hline \multicolumn{2}{|l|}{ POST APP } \\
\hline Patient $(n=19): P t$ & 19 interviews \\
\hline Clinician researcher $(n=2)$ : $\mathrm{Dr}$ & 3 interviews \\
\hline \multicolumn{2}{|c|}{ CLINICAL CONSULTATIONS - POST APP } \\
\hline $\begin{array}{l}\text { Patient }(n=17)+\text { clinician } \\
\text { researcher }(n=2)\end{array}$ & 17 clinical consultations \\
\hline
\end{tabular}

